\title{
Food Security As Resilience: Reconciling definition and measurement ${ }^{\#}$
}

\author{
Joanna B. Upton, Jennifer Denno Cissé, and Christopher B. Barrett \\ Charles H. Dyson School of Applied Economics \& Management, Cornell University
}

July 2015

\begin{abstract}
:
In this paper, we draw out a set of axioms for food security measurement that follow directly from the internationally agreed 1996 FAO definition. Building on recent work on the theory and measurement of development resilience, we then propose an empirical strategy to measure food security that addresses these measurement axioms better than do prevailing measures. We empirically illustrate this approach using a panel data set from northern Kenya.
\end{abstract}

\footnotetext{
\# This paper was prepared under a cooperative agreement with the United States Department of Agriculture's Economic Research Service, Market and Trade Economics Division. We thank Paul Christian, Mark Constas, Brady Deaton, Megan Sheahan, Sharad Tandon and participants at the February 2015 USDA ERS workshop on "Finding Meaning in Our Measures: Overcoming Challenges to Quantitative Food Security Assessments" for helpful comments on an earlier draft. Any remaining errors are our responsibility alone.
} 


\section{Introduction}

The consensus definition, internationally agreed at the 1996 Food and Agriculture Organization Food Summit, holds that food security exists if and only if "all people at all times have physical, social, and economic access to sufficient, safe and nutritious food that meets their dietary needs and food preferences for an active and healthy life" (FAO 1996, henceforth FAO definition). A primary purpose of a precise, agreed definition is to provide a template for understanding the problem, designing solutions, targeting policies, and assessing progress. A definition thereby implicitly offers axioms for measurement, which is the main "driver of diagnosis and response" (Barrett 2010, 827). While there is widespread agreement that measuring food security is important, the crucial question of how to do so remains contentious and unclear.

Food security measurement has progressed over the past half century or more, albeit imperfectly. From the 1950s-1970s, the focus was on national-level, supply-side availability of sufficient food to feed a growing population, with keen awareness of shocks to production and food prices (Maxwell and Smith 1992). In the early 1980s, focus turned increasingly to the demand side of food security, to individuals' capacities to access food in order to feed themselves. More recently, focus has turned to the utilization of foods through proper nutrition, preparation and feeding practices, and the stability of these conditions over time. (Maxwell and Smith 1992; FAO 2006; FAO 2008).

Availability, access, utilization, and stability are now widely accepted as the four pillars of food security. While many efforts have been made to measure food security, given the inherent unobservability of food security status and the formidable challenges of establishing measures that can be aggregated from individuals to multinational regions, it 
is unsurprising that measurement efforts fall short of maintaining fidelity to the FAO definition (Headey and Ecker 2012; Barrett 2002, 2010). Aggregate assessments rely on a range of strong assumptions in order to describe the food security of sub-groups. These aggregates tell us little or nothing about the utilization of foods, nor about change over time. Household-level indices inform about individual-level consumption and can encompass availability, access, and/or utilization. They do not, however, typically assess the health or nutritional state of individuals, and are also mostly static, which can grossly misstate both inter-seasonal variability in food consumption and inter-annual changes in conditions. And unless the individual level data are drawn from nationally representative surveys, they are not aggregable to nation state levels.

Furthermore, the ability to measure food security accurately has been subject to political constraints, especially the need on the part of international organizations to respect the sovereignty of national governments' own data collection protocols. Furthermore, while household- and individual-level data may better address outcomes and allow for aggregation when nested in statistically representative sampling designs, such exercises are analytically challenging and expensive, especially in a systematic and repeated manner over time. These constraints are easing as new technologies obviate the need for ground-based data collection (Brown et al. 2008; 2009) and organizations such as the World Bank fund the collection of high-quality, nationally representative, longitudinal housholed survey data that present opportunities to improve food security measures.

In this paper we propose a set of axioms for food security measurement that follow directly from the FAO definition. We then discuss the challenges and trade-offs inherent in satisfying those axioms, demonstrated by the range of food security measures currently in 
widespread use. Finally, we briefly discuss a promising new method for measuring food security that builds on the recent popularity of and analytical work in development resilience (Barrett and Constas 2014). We show that a resilience approach to food security measurement allows for enhanced capacity to satisfy the axioms implied by the FAO definition, enabling a more nuanced and useful metric than has been previously possible. We provide a simple illustration of the application of this metric to describe the food security situation of rural households in northern Kenya over the period preceding and following the catastrophic drought that struck the Horn of Africa in 2011. We close by outlining the data collection and other infrastructure that could pave the way to make this resilience-based approach to measuring food security operationally feasible.

\section{Evolving food security definitions}

Modern concerns with "food security" formally emerged with the global food crisis of 1973-74. The World Food Conference in 1974 defined food security as: "Availability at all times of adequate world food supplies of basic foodstuffs to sustain a steady expansion of food consumption and to offset fluctuations in production and prices" (FAO 1996, pg. 1). This definition reflected the then-prevailing emphasis on supply side constraints. Measurement of food security under the 1974 definition concerned global and national-level supplies of 'basic foodstuffs', with all calories treated as nutritionally equivalent and within-country access and distribution largely ignored. "Fluctuations in production and prices" were considered important, which implied measurement of production levels around the world and trends in food prices, little more. 
As the food security discussion evolved, focus gradually diverged between the notion of food security as a national and international supply phenomenon to a matter of household and individual-level access. The FAO proposed a revised definition in 1983, that food security meant "Ensuring that all people at all times have both physical and economic access to the basic food that they need" (FAO 1996, pg. 1). No international consensus emerged around this definition, however, so disparate definitions proliferated reflecting different concepts and priorities (Maxwell and Smith 1992).

A primary distinction between the various working definitions in the 1980s and 1990s remained the focus on the macro, or national, level versus the on households or individuals, i.e., populations on average versus "all people." This divergence in part reflects the goals and incentives of concerned actors. Those concerned with policy to improve child health, for example, demand a focus on individuals and/or sub-groups (such as nursing mothers), whereas for those concerned with international politics and trade, national averages might suffice.

Another key point of divergence concerned the time dimension, as reflected in the "at all times" component of the 1983 FAO definition. The World Bank (1986) emphasized the importance of "chronic versus transitory" food insecurity. Chronic food insecurity is typically associated with structural problems of availability, access, or utilization, whereas transitory or acute food insecurity is associated with sudden and temporary disruptions. This temporal component highlights the need to address how food security changes with 1 ) cyclical phenomena like production seasons, 2) long-term trends like climate change, and 3) acute shocks of both natural and human origin. Increasingly, food security definitions 
mentioned risk or time, such as "access to the food needed for a healthy life for all members ...not at undue risk of losing such access" (ACC/SCN 1991).

The other innovation relative to the 1974 definition was the focus on "both physical and economic access." Physical access recognizes the need for infrastructure and food markets, while economic access highlights the roles that poverty reduction, social protection policies and informal support mechanisms play in ensuring food security. The growing attention to access in the 1980s and 1990s was heavily influenced by Sen's (1981) work on hunger and individual entitlements. An entitlement is the set of consumption bundles a person can obtain through whatever means available, respecting his/her endowments and rights. The concept promotes a broader perspective of human rights and individual well-being, along with intertemporal stability.

Two additional elements that emerged in the broader literature were 1) food safety and quality and 2) a focus on health and nutrition-related outcomes. Certain writers and agencies started to address the former by bringing in concepts of nutritional adequacy and "adequate quantity and quality" (Maxwell and Smith 1992). Other authors focused on outcomes, such as health (VonBraun 1991) and productivity (World Bank 1986).

\section{Food Security Measurement Axioms}

The 1996 FAO Food Summit proposed the definition that finally integrated these concepts: "all people at all times have physical, social, and economic access to sufficient, safe and nutritious food that meets their dietary needs and food preferences for an active and healthy life". In principle, food security measurement should follow directly from the FAO definition. Correspondingly, the ideal food metric would satisfy four basic axioms: 
1) Relate to "all people," addressing both individuals and groups at any scale of aggregation, including geographic regions and political jurisdictions. We refer to this as the scale axiom.

2) Apply "at all times," encompassing both predictable and unpredictable variability over time. We refer to this as the time axiom.

3) Capture the notion of "physical, social and economic access," as manifest in relation to various indicators of individual and collective well-being. We refer to this as the access axiom.

4) Ultimately relate to dietary, health, and/or nutrition outcomes required for "an active and healthy life." We refer to this as the outcomes axiom.

To date, no food security measure satisfies these four axioms. The global community has relied heavily on proxy measures that attend to one, two or perhaps three of these axioms. Many of these proxy measures are important and useful, but they are necessarily incomplete.

There are also other important criteria by which to judge different measures of food security, including the cost of implementing a metric, as well as the comparability between groups (Headey and Ecker 2012). Such practical concerns impede near-term introduction of the measure we develop and illustrate below, especially due to data challenges, as we discuss in the next section. All the same, static proxy measures poorly reflect food security under the FAO definition. Recent innovations in the theory and measurement of stochastic well-being dynamics offer some promise for fruitful innovations in food security measurement. 


\section{Data challenges}

Data limitations and pragmatic concerns have undermined a direct and complete link between definition and measurement. As argued above, the ideal metric of food security would involve accurate, detailed data on the health and well-being of individuals, aggregable to larger groups, that covers a long span of time, and can be linked to other data on infrastructure, prices, and natural and other shocks.

One set of data challenges is primarily political. Any agency or government seeking to collect data in another country must have its agreement, vis-à-vis both what and how to measure. This can be a particular challenge in conflict zones, where governments may hinder rather than support efforts concerning opposing sub-populations within their own countries. Such political issues have particular salience with UN agencies like the FAO and WFP, often restricting them to rely on government data sources that vary in quality and reliability and/or hindering efforts to undertake data collection or assessment.

Additional challenges concern the nature and quality of data needed. A metric of food security should apply at the household or individual level, but household and individual-level data are difficult and costly to collect, placing a premium on skillful sampling design and implementation, but leaving open the possibility of considerable sampling and measurement error. Data quality can also be limited due to methodological issues with self-reporting, recall periods, and proxy reporting. Data are most often collected at the household-level, which ignores issues with inequitable intra-household allocation. Finally, comparability between data sets is often limited by differences between data collection instruments, variable definitions, training of field enumeration staff, data entry protocols, and so on. 
To date, the most common approach to food security measurement has been to use aggregate estimates, such as national-level food availability. These data often suffer even greater measurement error, because gaps are filled by estimates and extrapolations, aggregate measures are typically more vulnerable to political influence, and disaggregations commonly rely on applying strong, abstract assumptions (e.g., about the distribution of nutrients within a population). It is a well-documented fallacy to suppose that these 'best guess' assumptions, even when applied with great care and forethought, can have precise meaning when it comes to understanding the food security of individuals (Achen and Shively 1995).

An additional challenge lies in collecting data consistently over time. Short funding time-scales limit the timespan of many efforts. Even when data are collected over time, the exact nature of the indicators may change as the manner of collection evolves with the succession of institutions and/or individuals. Household and individual data can also suffer from non-random attrition due to migration, death, withdrawal from surveys, and the cost and complexity of fielding high frequency follow-ups of the same respondents.

Another constraint concerns the need for complementary data on infrastructure, institutions, the resource base, and shocks over time. Where they exist, these (like all) data suffer from quality shortfalls, international non-comparability, and inconsistency in collection practices. In recent years, geo-referencing has made matching of data across sources more reliable, although that introduces added risk of measurement error.

Most problematically, these data challenges are typically worst where food security problems are greatest. All of these constraints have evolved over time, however, with 
academic and governments' efforts, global cooperation, and technology opening up new, and typically improved, measurement opportunities.

\section{Existing metrics}

Working within the constraints and data challenges discussed above, a range of metrics have developed over the years. These can be divided broadly into two categories. One group comprises aggregate, national-level indicators which are then sometimes disaggregated to apply to smaller groups and/or individuals. The second encompasses measures constructed using survey data from households or individuals, which may be aggregated to some group level depending on the survey size and sampling procedures. We

briefly review existing metrics in widespread use, first those based on aggregates and then those based on micro data. We then summarize these.

\section{a. Macro-level metrics and indicators}

The most long-standing and widely published and cited metric for food security is the prevalence of undernourishment, developed by FAO and published periodically in its State of Food Insecurity report. This metric assesses "sufficient food energy availability adequate to cover minimum needs for a sedentary lifestyle" (FAO 2013). It uses national level food balance sheets constructed from estimates of food production plus net imports less stockbuilding and wastage, combined with food consumption and income or expenditure data from sample household surveys, and other demographic information. It hence relies largely on national-level data as collected by national governments, and 
extrapolation from other data sources based on a series of strong (and largely untested) assumptions.

This metric is intuitive, and has the appeal of being loosely comparable between countries and/or regions. But it also falls well short of addressing the four axioms that emerge from the definition of food security. With respect to the first axiom, scale ("all people"), the prevalence of undernourishment metric attempts to disaggregate following an assumed distribution among households in any given country, but cannot verify the underlying distributional assumption. With respect to the second axiom, time ("at all times"), the metric falls short in implicitly assuming that food access is stable throughout the year. There is no specific reference to the third axiom, access ("physical, social, and economic access"), other than in so far as it can be taken into account by the assumed distribution of food energy.

Finally, the fourth, outcomes axiom concerns "...safe and nutritious food for an active and healthy life." The prevalence of undernourishment metric relates only to dietary energy (i.e., calories), implicitly assuming that all calories are equivalent, all available foods are safe to eat, and all individuals are healthy enough to absorb the nutrients they consume. The FAO metric also explicitly employs the dietary energy standard for a sedentary lifestyle which presupposes that the norm is to work physically inactive jobs, which seems inappropriate for the poorest, who work mainly in agriculture and other forms of physically demanding labor.

While the FAO has worked hard to adjust and improve this metric, the estimates remain disturbingly sensitive to changes in methods. For example, the first estimate of the prevalence of undernourishment for 1990, assessed in 1992, was 762 million, whereas 
using today's methods (but the same underlying data) the estimate for 1990 is closer to one billion. According to the current estimate, there has been a drop in the number of people malnourished, whereas according to the former estimate, there has not (Caparros 2014). Macro-scale estimates are highly sensitive to the assumptions and methods one uses. Seemingly innocuous adjustments can lead to hugely different headline policy implications, such as whether or not we are making progress in reducing food insecurity worldwide. This is problematic because measuring wide-scale progress is one of the few practical uses of such a metric.

The Economic Research Service (ERS) of the United States Department of Agriculture (USDA) also constructs an international prevalence of food insecurity metric, along with related "nutrition gap" and "distribution gap" indices. ERS employs FAO data on historical production, FAO estimates of future production, World Bank macroeconomic data, and estimates of food aid based on averages provided in prior years (Shapouri et al. 2011). The first indicator estimates the number of food insecure individuals around the world and in each country of focus. The "nutrition gap" assesses the degree of food shortage by country, based on population, national availability, and an estimated minimum dietary energy requirement of 2100 calories per person per day. The "distribution gap" reflects the difference between projected availability and the additional food needed to increase the food consumption of food deficit income groups. Various proposals have been put forward within ERS to improve these indices. As with the FAO's undernourishment measure, the USDA metric relies on aggregate data and various assumptions to which it is quite sensitive. 
An additional category of macro-level metrics is less part of an attempt to measure the prevalence of food insecurity than to provide warning of potential crises. An important example is the United States Agency for International Development (USAID) Famine Early Warning System (FEWS). FEWS was created as a set of tools for governments and nongovernmental decision makers to better prepare and respond to humanitarian crises, with a focus on food security emergencies. FEWS uses the Integrated Phase Classification (IPC) system, a consensus-building process relying on a network of partners and diverse sources of data on production patterns, climate conditions, and other factors to rate the severity of food emergencies (FEWS 2014). The ideas and methods behind FEWS fed into the development of the FAO's Global Information and Early Warning System (GIEWS). A similar range of data sources are used, including weather and climate information as well as regional news reports and other sources. The FEWS, GIEWS and IPC measures are aggregates not really aimed at the all people part of the FAO definition and typically do not attend to the active and healthy life axiom either; their focus, as forecasting methods, is primarily on the time dimension, and on projecting future conditions in order to plan humanitarian interventions.

Other metrics have been developed in recent years, with various nuances in focus and/or intended audience. The International Food Policy Research Institute (IFPRI) produces the Global Hunger Index, an equally weighted index based on three separate indicators - undernourishment, child underweight, and child mortality - and uses primarily aggregated survey data collected by the FAO, UNICEF, and the WHO (von Grebmer et al. 2013). This metric is similar to the FAO and other aggregate measures, but with a greater focus on outcomes related to child health and nutrition. Still another index- 
based approach, the Economist Intelligence Unit's food security index, uses diverse data sources to combine and weight 28 indicators (Economist Intelligence Unit 2015). These index measures offer simple, scalar representations of a complex array of information, and attempt to address both the access and outcomes axioms. They also, however, suffer from the same shortcomings as other aggregate methods. Additionally, indices are intrinsically difficult to interpret for policy purposes; while one can use them to rank countries relative to each other, the causes of food insecurity are obfuscated by the combination and weighting of different factors.

\section{b. Micro-level metrics and indicators}

Indicators that focus on households or individuals are usually based on survey data. They can be separated into several categories, each reflecting a different area of emphasis and implicit definition or focus of food security.

Household income and expenditure indicators use survey data to measure householdlevel income, assets, and/or expenditure, as a metric for poverty and well-being. These can be used as a proxy or indicator of food security, with a clear focus on the economic component of the access axiom.

Dietary diversity and/or food consumption indicators use survey data on food consumption, such as a recall of foods eaten and their frequency or weights and measures based on direct observation, and then construct an indicator for food consumption and/or dietary diversity. These include:

(1) The Food Variety Score (FVS) or Household Dietary Diversity Index (HDDI), a count of the number of different food items consumed in the past week; 
(2) The Dietary Diversity Score (DDS), a count of food groups consumed;

(3) The Food Frequency Score (FFS), a sum of food groups that integrates the frequency of consumption of each food group;

(4) The Food Consumption Score (FCS), which adds to the FFS by weighting food groups based on their nutritional quality.

The Coping Strategies Index (Maxwell et al. 2003; Maxwell and Caldwell 2008), is an index based on the responses to a series of questions about the occurrence and frequency of various food-related strategies, such as the need to beg or borrow to procure food, reduce meal frequency or portions, or consume seed stocks. These questions capture information primarily about access to foods. Related metrics include the Household Food Insecurity Access Scale (HFIAS) and the Household Hunger Scale (HHS), which use similar types of questions to assess household-level food access (FAO 2012).

Subjective or experiential indicators ask households or individuals to report their personal sense of their food security. ERS uses these metrics for domestic food security measurement within the U.S., and various research groups have applied variants of these indicators in developing countries (Webb et al. 2006, Coates 2013). These subjective indicators have superior potential to assess a number of facets of food security, such as social access or the sufficiency of foods to meet food needs and preferences that remain otherwise difficult to directly measure. When combined with latent trait statistical modeling methods, such data can, in principle, permit representation of the intrinsically unobservable and heterogeneous food security status within a population (MelgarQuinonez et al. 2008, Rafiei et al. 2009, Nord 2012). But like all subjective measures, they are vulnerable to unobserved, non-random heterogeneity. 
Anthropometric measures use relatively simple data collection procedures to assess the growth and development of individuals, most commonly infants and young children. These indicators include adult measures such as the body mass index, child malnutrition indicators such as the height-for-age ratio to estimate rates of stunting, and the weight-forheight ratio or Mid-Upper Arm Circumference (MUAC), to estimate rates of wasting. These metrics are arguably best at assessing food security outcomes, albeit setting aside the underlying causes of food insecurity.

\section{c. Summary}

Figure 1 summarizes, in a stylized manner, the broad classes of food security measures that presently exist, in terms of the four axioms. The horizontal axis signifies time; indicators further to the right perform better in assessing how food security changes over time and/or responds to shocks. The vertical axis represents scale; indicators higher on that axis are more adaptable in terms of being able to represent both individuals and aggregate groups of interest. The marker diameter for the indicator indicates the degree to which it captures the idea of access, with larger indicators performing better. Finally, the shading of the indicator reflects the degree to which it captures health and nutrition outcomes, with darker markers performing better. Therefore, larger and darker indicators that lie in the northeast of Figure 1 go further to capture the four axioms of food security measurement implied by the FAO definition.

One must, however, exercise caution in such a normative framing. While we can indeed rank indicators in terms of how well and completely they represent the axioms implied by the FAO definition, we must also take into account the context and needs, as 
well as the cost of acquiring and processing data in light of its usefulness for a particular application. For example, for some applications an aggregate measure may suffice, making an individual-level measure not worth the cost and challenge. In turn, while health and nutrition may be the ultimate outcomes of interest in food security, policymakers need data on availability, access, or other pillars so as to identify the root causes when these outcomes are unsatisfactory.

It is important to note that any individual-level measure can meet the scale axiom with appropriate sample size and representative selection. Similarly, one-off and annual measures could be gathered more frequently in order to satisfy the time axiom. For example Chotard et al. (2010) estimate of fluctuations of wasting in the Horn of Africa, using static household surveys at different periods to draw attention to the importance of seasonal patterns.

The key take-away of Figure 1 is that none of the current classes of food security measures satisfies all four axioms satisfactorily. There are sharp tradeoffs inherent to using one versus another type of indicator, and a measure akin to number 8 in this diagram, which meets all axioms, remains elusive. As a result, policy makers currently must gather information from several measures in order to piece together a satisfactory understanding of food security in any given context.

\section{Adapting development resilience for food security measurement}

Recent advances in development resilience measurement offer a potential solution to satisfy these unmet food security measurement needs. Barrett and Constas $(2014, \mathrm{BC}$ hereafter) advance a theory that focuses explicitly on the stochastic dynamics of well-being 
measures at multiple scales of analysis. They define development resilience as "the capacity over time of a person [or] household... to avoid poverty in the face of various stressors and in the wake of myriad shocks. If and only if that capacity is and remains high over time, then the unit is resilient" (p. 14626).

While BC focus on poverty and well-being broadly, individual or household indicators of food security can easily substitute as the primary well-being variables of interest. Conditioning on lagged values of the dependent variable explicitly allows for nonlinear path dynamics and the possibility of chronic food insecurity associated with poverty traps. BC advocate a moments-based approach, which estimates the conditional distribution of well-being. One can then derive the probability of satisfying some normative standard of food security, specific to the outcome of interest. By relating the estimated probability of satisfying a health or nutritional standard to variables reflecting context and factors amenable to intervention, one can then identify both targetable characteristics of the food insecure and, potentially, actions that can advance food security objectives reflected in all four axioms.

Cissé and Barrett (2015, hereafter CB) show how this measure can be implemented econometrically in household or individual survey data. In particular, they show how one can estimate a system of conditional moment functions for a measure of individual or household well-being, construct time sequences of estimated probabilities of falling beneath some normatively-defined minimum standard for that well-being indicator, derive an estimate of each individual's resilience from those probability estimates, and identify the (potentially causal) factors associated with resilience. They then explain how one can aggregate individual resilience measures across individuals to construct group-level 
measures. This aggregability is particularly important for the targeting of interventions, as it allows one to identify the most food insecure or vulnerable groups based on readily observable indicators, such as gender or geographic location.

With adequate data and employing the CB method, this development resilience approach can measure food security in a way that meets all four of the food security measurement axioms:

1) By identifying food security at the individual or household level, the measure is aggregable into higher-level groups (social groups, regions, etc.), thereby satisfying the scale axiom.

2) The approach is explicitly dynamic, thereby satisfying the time axiom.

3) One can condition the moments of the food security distribution on any of a host of economic, physical and social factors, thereby satisfying the access axiom.

4) If one uses suitable measures of health or nutritional status as dependent variables, this method satisfies the outcomes axiom.

Although this model holds promise for improving the measurement of food security and program impacts, the key limitation remains data. Estimation of the conditional moments functions is computationally intensive, putting a premium on the frequency and quality of data. One also needs to follow the same units over time, ideally at seasonal frequency, with data on a variety of factors that contribute to food security, including both covariate and idiosyncratic shocks. Market, weather and environmental data are equally essential.

We remain a long way from having access to such data other than in a few unusual cases, in large part because such data are expensive to collect. Despite calls for an 
international system of sentinel sites to provide high-frequency, micro-level data from some of the world's most food insecure countries (Barrett 2010; Headey and Barrett 2015), there is little prospect in the coming decade or so of sufficient quality, high frequency, and geographic coverage of data to be able to provide reliable global food security estimates. Nonetheless, the insights we can glean from a resilience approach to food security measurement are instructive. And where such data exist, there is value in implementing these measures, as the example that follows illustrates.

\section{An empirical example from northern Kenya}

In this section, we employ the CB method discussed above to estimate the food security of rural households in northern Kenya. The data were collected annually in October-November from 2009 through 2013, inclusive, by a team led the International Livestock Research Institute (ILRI) (ILRI 2013). The surveys were designed to capture a wealth of household livelihood and welfare data for 924 survey households in Marsabit District (now County) and include general demographic questions as well as questions regarding livestock production, risk and insurance, employment, expenditure and consumption, assets, and savings and credit, in addition to anthropometric measures of children under five years of age.

\section{a. Resilience categorization}

For this example, we use dietary diversity and child anthropometry as our wellbeing indicators of interest, specifically the household dietary diversity score (HDDS) and child mid-upper arm circumference (MUAC). These satisfy the outcomes axiom as 
indicators of "an active and healthy life." We can relate these measures to a range of individual, household and community characteristics that collectively satisfy the access axiom. The method and duration of the data satisfy the time axiom — albeit only at annual frequency — and we can aggregate the individual estimates into group-level measures, thereby satisfying the scale axiom. This example thus offers a compact illustration of how individual- or household-level panel data can be used to establish food security measures that satisfies all four axioms implied by the FAO definition of food security.

We must first determine an appropriate minimum threshold level of the chosen outcome. HDDS is calculated using household-level, seven day recall data which allows us to count the number of food groups (out of a total of twelve) consumed by household members during the past week. There is no internationally accepted minimum standard for household dietary diversity, but FANTA III (Swindale and Bilinsky 2006) recommendations for HDDS target setting are commonly referenced in the literature. We follow these recommendations and set the minimum HDDS threshold equal to the mean HDDS of the wealthiest third of sample.

At individual child level, we use the WHO child growth standards to set the threshold level of MUAC at $\underline{W}=-1$ standard deviation (SD) in terms of a child's genderand age-appropriate MUAC (WHO 2015). Food security is then a function of the estimated probability that the child will surpass the MUAC threshold $(\underline{W})$ in each period.

We begin econometrically by estimating conditional mean HDDS and MUAC regression equations and then use the residuals from the conditional mean equations to similarly estimate conditional variance as a function of community, household and individual characteristics. While this approach allows for the use of higher-order moments 
beyond variance, for present illustrative purposes we assume that HDDS and MUAC are normally distributed, so that the first two conditional moments (mean and variance) fully describe each well-being conditional distribution.

To allow for nonlinear dynamics, we model each well-being indicator as a thirdorder polynomial in the lagged value of itself (i.e., HDDS and MUAC from the previous period), a dummy variable for drought equaling one for cases in which the normalized difference vegetation index NDVI predicted livestock mortality greater than $15 \%$; the sex, age, squared age, and years of education of the household head; the household dependency ratio; and household livestock holdings in terms of tropical livestock units(TLU). ${ }^{1}$ We estimate the mean HDDS and MUAC equations using ordinary least squares with robust standard errors. See CB for more details on the variables and estimation methods used.

The conditional mean HDDS equation estimates appear in column (4) of Table 1. The statistically significant third order polynomial relationship between HDDS and its lagged value suggests strong nonlinear path dynamics in dietary diversity. The drought indicator variable (predicted livestock mortality $>15 \%$ ) has a strong, negative effect on HDDS, while having a well-educated head of household is positively correlated, perhaps picking up omitted income that is positively associated with both variables.

We capture the residuals $(e)$ from the conditional mean HDDS equation, square them, and then regress these values $\left(e^{2}\right)$ on the same covariates to estimate conditional variance, $\mathrm{V}(\mathrm{HDDS})$, constraining the estimation to allow only positive estimates for conditional variance. The estimation results, reported in column (5) of Table 1, confirm

${ }^{1} 1 \mathrm{TLU}=1 \mathrm{cow}, 0.7$ camel, 10 sheep, or 10 goats. 
that there exist nonlinear dynamics in the conditional variance and that households with larger livestock holdings have more stable dietary diversity.

We use the conditional mean and variance estimates to parameterize individualspecific probability density functions (PDFs) of HDDS, as it relates to the HDDS threshold of 7.9 food groups. We use the estimated probability of a household attaining this threshold value representing adequate HDDS in a given year as that household's food security score for each period. We then explore which household characteristics correlate with food security, thus defined. We regress the household-specific food security measure - which falls in the $[0,1]$ interval - on the same household characteristics used in the conditional mean and variance equations and report those findings in column (6) of Table 1. Intuitively, drought is negatively and significantly correlated with food security, while education is strongly, positively associated with food security. Even though the demographic variables age of household head and dependency ratio were not statistically significantly related to either the conditional mean nor conditional variance of HDDS, they are significantly correlated with food security because of the joint effects. Households' food security declines with its dependency ratio and with head's age up to 46 years, after which it improves. The importance of demographic characteristics - which serve as useful indicator targeting criteria - appear even more clearly when we aggregate resilience scores across sub-groups, as we demonstrate below.

With regards to the second food security indicator, child MUAC, the coefficient estimates from the conditional mean and variance MUAC equations can be found in columns (4) and (5) of Table 2. The statistically significant third order polynomial relationship between mean MUAC and its lagged value suggests strong, nonlinear path 
dynamics in child anthropometry as with HDDS. MUAC is positively (negatively)and significantly associated with household head education (drought). Interestingly, MUAC is nearly homoscedastic, as none of the variables is individually statistically significant at the five percent level.

Just as with HDDS, we use the conditional mean and variance estimates to parameterize child-specific MUAC PDFs. Then we use the estimated conditional probability of each child attaining at least the -1 SD MUAC threshold as the child's food security score for each period. We regress this food security measure on the same household characteristics used in the conditional mean and variance equations and report those findings in column (6) of Table 2. The patterns are largely the same as with HDDS. Drought negatively and significantly affects food security. Head's education is positively and significant correlated with food security, while demographic characteristics that were statistically insignificantly associated with individual moments are significantly related to overall food security. The main change from the HDDS results is that a female head of household is negatively and significantly associated with child food security based on the MUAC indicator.

\section{b. Resilience Aggregation}

In order to aggregate individuals' estimated food security scores into an aggregate measure of food security, we use the CB method to construct an analog to the Foster, Greer and Thorbecke (1984, hereafter FGT) class of poverty measures. We first select a (inherently arbitrary) minimum food security probability threshold, $\underline{P}=0.25$. This implies that only households (children) with at least a $25 \%$ probability of reaching the well-being 
threshold $(\underline{W})$ of HDDS $\geq 7.9$ (MUAC $\geq-1 \mathrm{SD}$ ) are deemed food secure. As with FGT poverty measures, one can construct a food security headcount, gap or other measures depending on the distribution-sensitivity parameter used. We calculate the headcount, or proportion of children under five who are food secure. For the entire population in round 2 of the sample data, we estimate:

$$
\begin{gathered}
R_{H D D S, 0,2}(\boldsymbol{\rho} ; \underline{W}=7.9, \underline{P}=.25) \equiv 1-\left[\frac{1}{n} \sum_{i=1}^{q}\left(\frac{g_{i}}{\underline{P}}\right)^{0}\right]=0.371 \\
R_{M U A C, 0,2}(\boldsymbol{\rho} ; \underline{W=-1 \text { s.d. } .}, \underline{P}=.25) \equiv 1-\left[\frac{1}{n} \sum_{i=1}^{q}\left(\frac{g_{i}}{\underline{P}}\right)^{0}\right]=0.824,
\end{gathered}
$$

meaning that in round 2, just before the catastrophic 2011 drought struck, nearly 40 percent of households could be considered food secure in terms of HDDS and over 80 percent of the children in the MUAC sample could be considered food secure. We then divide the sample population into subgroups by targetable attributes such as the sex or education of the household head, geographic area, etc. The food security index for each subgroup is calculated by aggregating across the individual probability estimates for the subgroup members. An appealing feature of this decomposable index approach is that, by construction, the food security of the entire population is the same whether calculated based on representative data from the entire population or as the population-weighted sum of the various subgroups' food security levels.

We find that female-headed households have lower levels of food security than do male-headed households, both in terms of HDDS and MUAC-based measures (Figures 2 and 3). The mostly striking variation, however, is between households whose heads had no formal education and those with at least primary education (Figure 2). Furthermore, the adverse impact of the major drought that struck in period 3 (2011) appears significant only 
among the children in households with uneducated heads (Figure 3), not in householdlevel dietary diversity measures (Figure 2) nor in households with more educated heads.

This sort of dynamic disaggregation by subgroup can have important, actionable implications for targeting. This empirical exercise demonstrates the potential power and flexibility of the development resilience approach to food security measurement in providing information on specific populations or population segments while satisfying the axioms implied by the FAO definition of food security.

\section{c. Policy Advantages}

Another advantage of the development resilience approach to food security measurement, relative to a static measure of the average of a given outcome for a group or sub-group (or prevalence above a given threshold), is that it allows us look at the probability of maintaining food security over time. Rather than using cross-sectional variation as a proxy for inter-temporal variation-which we know it is not-we can leverage inter-temporal variation in prior periods as a better predictor of future outcomes. Moreover, by choosing $\underline{P}$ we can choose to minimize errors of exclusion, inclusion, or their sum, depending on operational priorities.

In order to assess the targeting accuracy of this approach to food security measurement, in particular relative to the prevailing approach that uses the most recently observed value of a household to predict its need for assistance in the next period, we compare targeting accuracy rates (both correctly targeted and correctly not targeted), Type I errors (errors of inclusion, i.e., those targeted who nonetheless exceeded the threshold) and Type II errors (i.e., errors of exclusion, those not targeted who nonetheless fell below 
the threshold), for different probability thresholds $(\underline{P})$, with the same targeting efficiency rates for the standard targeting approach based on the most recently observed value (Tables 3 and 4). Accuracy assessments are based on predicting the food security status in round 5 of the data using data observed for rounds 1-4, for both the HDDS and MUAC indicators.

In our simple example, and based on highly restrictive simplifying assumptions such as the normality of the household and child-specific food security distributions, the overall targeting accuracy (sum of the errors) may improve only marginally over the naïve estimate that values persist over time. Importantly, however, this approach allows implementers to favor Type I or Type II error, depending on operational preferences. In circumstances where the risks of non-intervention are severe and/or resources or scarce, errors of inclusion (Type I error) may be less grave, whereas where resources are especially limited want might prioritize minimizing leakage to unintended recipients (Type II errors). These estimates are conservative given the strong simplifying examples made in this illustrative exercise; using more flexible distributions, including nonparametric approaches, should help improve predictive accuracy further.

Finally, another benefit to the approach is that - in data sets where clean causal identification is feasible through experimental design, a natural experiment, or other methods - rigorous evaluation of the impact of alternative interventions on individual, population, or sub-population level food security would also be feasible with this method. Other food security measures largely lack the ability to combine inference, measurement, and prediction. 


\section{Conclusions}

In this paper we briefly reviewed the history of food security definitions and measures. We parse the internationally agreed 1996 FAO definition of food security to develop four specific measurement axioms related to scale, time, access, and outcomes. We then discuss the data challenges that constrain food security measurement currently and prevent any of the workhorse measures from satisfying these four axioms simultaneously. Different tradeoffs among axioms lead different groups to favor different options among the currently available food security measures.

We then illustrate how recent advances in the conceptualization and measurement of development resilience - building on Barrett and Constas (2014) and Cissé and Barrett (2015) - can be adapted to food security measurement in a manner that satisfies all four axioms. We then briefly illustrate an application of such a measure using five years' longitudinal household data from northern Kenya.

This new measure remains very much a work in progress. It remains infeasible to implement at scale given current limitations on nationally representative individual or household panel data availability. But this new measure suggests what could be attained if international development and humanitarian agencies resolve the public goods provision problem associated with high frequency, longitudinal data collection in the world's most vulnerable regions. The opportunity to develop robust, axiomatic measures of food security is considerable, as is the opportunity to improve food security programming through the use of improved measures for diagnosis, inference, prediction and targeting. 


\section{References}

Achen, C.H. and Shively, W.P., 1995. Cross-level Inference. Chicago,: University of Chicago Press, 1995.

Barrett, C.B., 2002. Food security and food assistance programs. Chapter 40 in. B.L. Gardner. and G.C. Rausser, eds., Handbook of Agricultural Economics, volume 2B, Amsterdam, Elsevier Science.

Barrett, C.B., 2010. Measuring food insecurity. Science 327: 825-828.

Barrett, C.B. and Constas, M.A., 2014. Toward a theory of development resilience for international development applications. Proceedings of the National Academy of Sciences 111 (40): 14625-14630.

Brown, M.E., Pinzon, J.E. and Prince, S.D. (2008). Using satellite remote sensing data in a spatially explicit price model: Vegetation dynamics and millet prices. Land Economics, 84(2): 340-357.

Brown, .M.E., Hinterman, B. and Higgins, N. (2009). Markets, climate change, and food security in West Africa. Environmental Science and Technology, 43(21): 8016-8020.

Caparros, M., 2014. Counting the Hungry. New York Times Sunday Review, September 27, 2014. Available on line at:

http://www.nytimes.com/2014/09/28/opinion/sunday/counting-the-hungry.html?_r=0.

Chotard, S., Mason, J.B., Oliphant, N.P., Mebrahtu, S. and Hailey, P., 2010. Fluctuations in wasting in vulnerable child populations in the Greater Horn of Africa. Food and Nutrition Bulletin, 31(3): S219-S233.

Cissé, J.D. and Barrett, C.B., 2015. A Moment-Based Approach to Resilience Measurement. Cornell University working paper.

Coates, J., 2013. Build it back better: Deconstructing food security for improved measurement and action. Global Food Security 2(3): 188-194.

Economist Intelligence Unit Limited, 2015. The Global Food Security Index. Available on line at http://foodsecurityindex.eiu.com (accessed February 10, 2015).

Famine Early Warning System, 2014. Our Work. Available on line at: http://www.fews.net/our-work (accessed September 25, 2014).

Food and Agriculture Organization, 2013. The State of Food Insecurity in the World. Available on line at: http://www.fao.org/publications/sofi/2013/en/

Food and Agriculture Organization, 2012. Integrated food security phase classification: Technical Manual Version 2.0. Evidence and Standards for Better Food Security Decisions. 
Available on line at http://www.ipcinfo.org/fileadmin/user_upload/ipcinfo/docs/IPCManual-2-Interactive.pdf.

Food and Agriculture Organization, 2008. An introduction to the basic concepts of food security. Food Security Information for Action Practical Guides. EC - FAO Food Security Programme. Available on line at http://www.fao.org/docrep/013/al936e/al936e00.pdf.

Food and Agriculture Organization, 2006. Food Security. Policy Brief, June 2006, Issue 2. Available on line at: http://www.fao.org/forestry/131280e6f36f27e0091055bec28ebe830f46b3.pdf (accessed October 15, 2014).

Headey, D. and Barrett, C.B., 2015. Measuring Development Resilience in the World's Poorest Countries. Proceedings of the National Academy of Sciences, in press.

Headey, D. and Oliver, E., 2012. Rethinking the measurement of food security: from first principles to best practice. Food Security 5(3): 327-343.

Lappé, F.M., Clapp, J., Anderson, M., Broad, R., Messer, E., Pogge, T. and Wise, T., 2013. How we count hunger matters. Ethics and International Affairs, pp. 1-9.

Maxwell, D.G. and Caldwell, R., 2008. The coping strategies index: A tool for rapid measurement of household food security and the impact of food aid programming in humanitarian emergencies. Field Methods Manual, $2^{\text {nd }}$ Edition, January 2008. Available at: http://home.wfp.org/stellent/groups/public/documents/manual guide proced/wfp2110 58.pdf (accessed October 18, 2014).

Maxwell, D.G., Watkins, B., Wheeler, R., and Collins, G., 2003. The Coping Strategies Index: A tool for rapidly measuring food security and the impact of food aid programmes in emergencies. FAO International Workshop on "Food security in complex emergencies: building policy frameworks to address longer-term programming challenges." Tivoli, 23-25 September 2003. Available at: http://www.fao.org/crisisandhunger/root/pdf/maxwell.pdf (accessed October 18, 2014),

Maxwell, S. and Smith, M., 1992. Household food security: a conceptual review. In Maxwell, Simon and Timothy Frankenberger (Eds). Household food security: concepts, indicators, measurements, A Technical Review. New York and Rome: UNICEF and IFAD

Melgar-Quinonez, H. R., Nord, M., Perez-Escamilla, R. and Segall-Correa, A.M., 2008. Psychometric properties of a modified US-household food security survey module in Campinas, Brazil, European Journal of Clinical Nutrition 62, 5: 665-673.

Nord, M., 2012. Assessing potential technical enhancements to the US Household Food Security Measures. USDA-ERS Technical Bulletin no. 1936.

Rafiei, M., Nord, M., Sadeghizadeh, A. and Entezari, M.H., 2009. Assessing the internal validity of a household survey-based food security measure adapted for use in Iran. Nutrition Journal 8, 28: 1186-97. 
Rosen, S. and Shapouri, S., 2002. Measuring access to food in developing countires: The case of Latin America. Chapter in Measurement and Assessment of Food Deprivation and Undernutrition, International Scientific Symposium, Rome, 26-28 June 2002.

Sen, A., 1981. Poverty and famines: an essay on entitlement and deprivation. Oxford: Oxford University Press.

Swindale, A., and Bilinsky, P., 2006. Household Dietary Diversity Score (HDDS) for Measurement of Household Food Access: Indicator Guide VERSION 2. USAID, FANTA III.

Shapouri, S., Rosen, S., Peters, M., Tandon, S., Gale, F., Mancino, L. and Bai ,J., 2011. International Food Security Assessment, 2011-2021. USDA Economic Research Service, July 2011.

UNESCO, 2014. Guide to Archives of International Organizations. On line at http://www.unesco.org/archives/sio/Eng/presentation print.php?idOrg=1011 (accessed September 10, 2014).

Von Grebmer, K., Headey, D., Olofinbiyi, T., Weismann, D., Fritschel, H., Yin, S., Yohannes, Y., Foley, C., von Oppeln, C., Iseli,, B., Bene, C. and Haddad, L., 2013. The challenge of hunger: Building resilience to achieve food and nutrition security. IFPRI 2013.

Webb, P., Coates, J., Frongillo, E.A., Rogers, B.L., Swindale, A. and Bilinsky, P., 2006. Measuring household food insecurity: Why it's so important and yet so difficult to do. Journal of Nutrition 136: 1404S-1408S.

World Food Summit, 1996. Rome Declaration on World Food Security.

World Health Organization, 2015. Child Growth Standards: Methods and development: Head circumference-for-age, arm circumference-for-age, triceps skinfold-for-age and subscapular skinfold-for-age. World Health Organization. On line at: http://www.who.int/childgrowth/publications/technical_report_2/en/ 


\section{Tables and Figures}

Figure 1: The performance of stylized food security metrics against the four measurement axioms implied by the FAO definition of food security

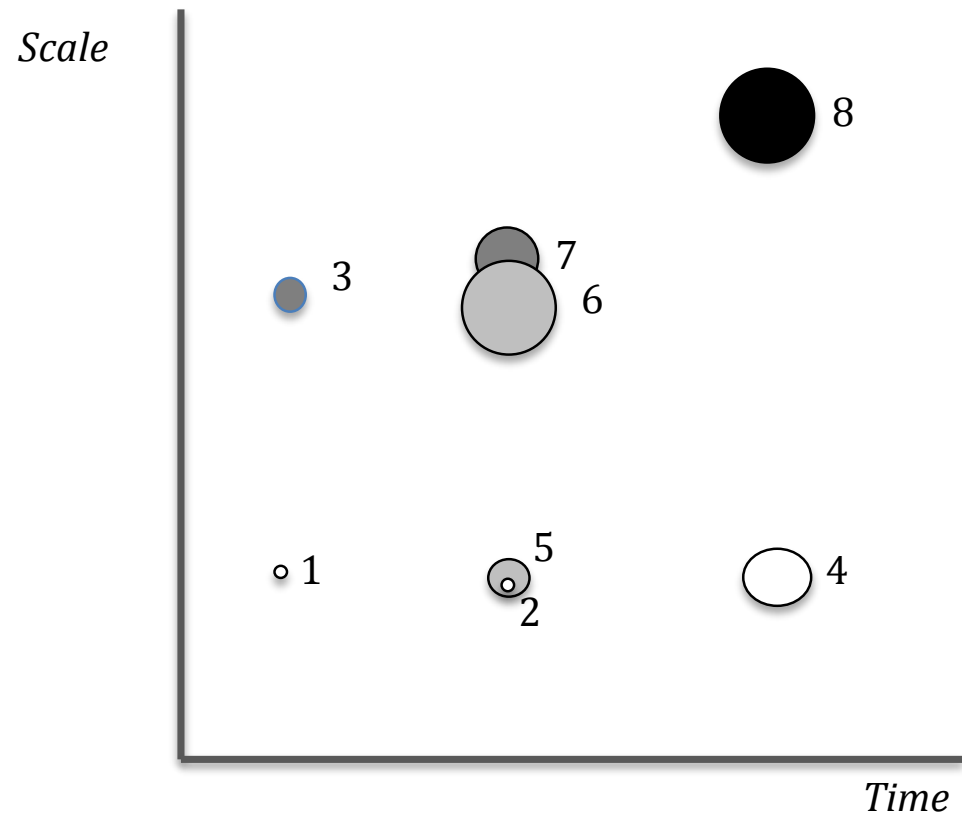

Larger size indicates better representation of the access axiom Darker color indicates better reflection of the outcomes axiom

\begin{tabular}{|ll|}
\hline Key: & $\begin{array}{l}\text { One-off aggregate (e.g. national level) indicator } \\
\text { of food availability }\end{array}$ \\
\hline 1 & Annual aggregate indicator of food availability \\
\hline 3 & $\begin{array}{l}\text { One-off household-level indicator of food } \\
\text { consumption or dietary diversity }\end{array}$ \\
\hline 4 & $\begin{array}{l}\text { Repeated, high frequency indicator of aggregate } \\
\text { food availability and access (e.g., localized } \\
\text { production conditions, climate, infrastructure) }\end{array}$ \\
\hline 5 & $\begin{array}{l}\text { Annual aggregate composite indicator of food } \\
\text { availability, access, poverty and inequality, and } \\
\text { other institutional factors }\end{array}$ \\
\hline 6 & $\begin{array}{l}\text { Annual indicator of household-level poverty } \\
\text { Annual indicator of household-level food } \\
\text { consumption or dietary diversity }\end{array}$ \\
\hline 7 & $\begin{array}{l}\text { Repeated high frequency indicator of individual- } \\
\text { level dietary diversity and/or health }\end{array}$ \\
\hline
\end{tabular}


Figure 2:

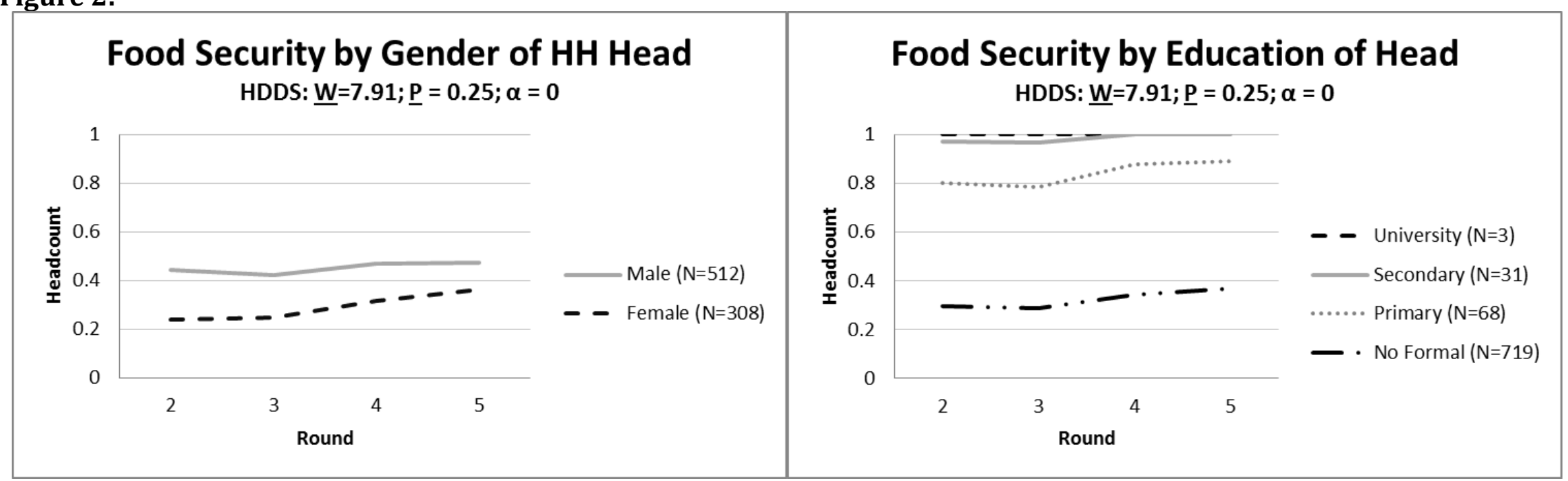

Figure 3:

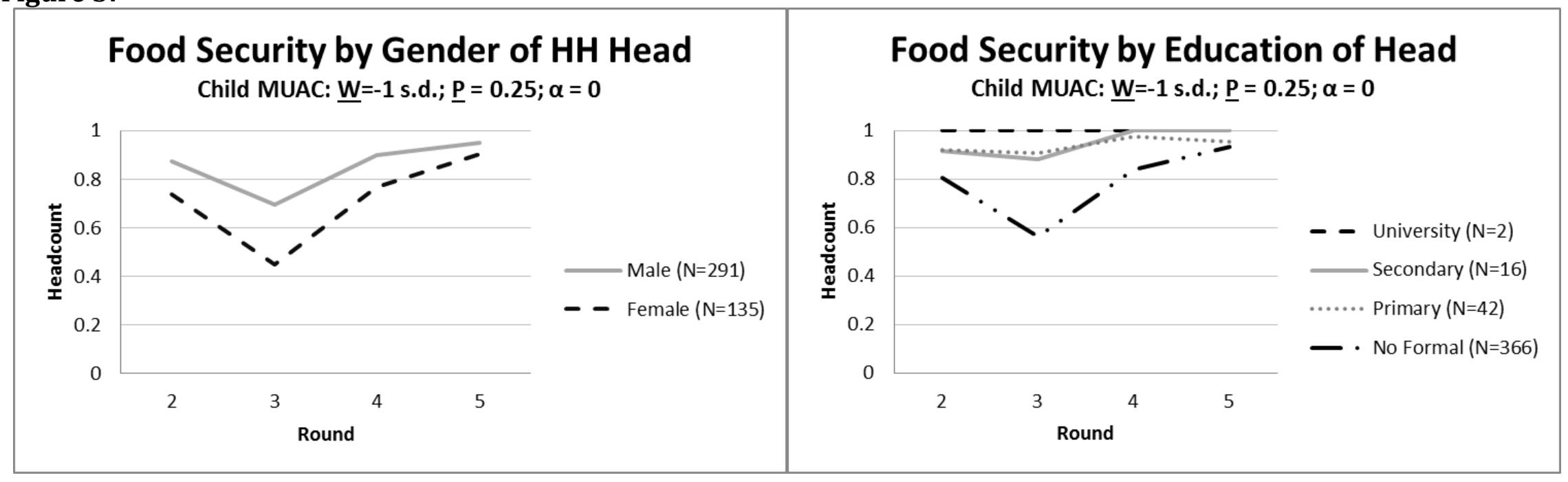


Table 1: OLS estimates of Household Dietary Diversity Score (HDDS), Variance(HDDS), \& Food Security

\begin{tabular}{|c|c|c|c|c|c|c|}
\hline VARIABLES & $\begin{array}{c}(1) \\
\text { HDDS } \\
\end{array}$ & $\begin{array}{c}(2) \\
\text { HDDS } \\
\end{array}$ & $\begin{array}{c}(3) \\
\text { HDDS }\end{array}$ & $\begin{array}{c}(4) \\
\text { HDDS } \\
\end{array}$ & $\begin{array}{c}(5) \\
\text { V(HDDS) }\end{array}$ & $\begin{array}{c}(6) \\
\text { Food Security }\end{array}$ \\
\hline HDDS_lag & $\begin{array}{l}0.466^{* * *} \\
(0.0174)\end{array}$ & $\begin{array}{c}-0.247^{* *} \\
(0.124)\end{array}$ & $\begin{array}{c}-1.925^{* * *} \\
(0.386)\end{array}$ & $\begin{array}{c}-1.237^{* * *} \\
(0.381)\end{array}$ & $\begin{array}{c}-1.363^{* * *} \\
(0.437)\end{array}$ & $\begin{array}{c}-0.334^{* * *} \\
(0.0146)\end{array}$ \\
\hline HDDS_lag2 & & $\begin{array}{l}0.0501^{* * *} \\
(0.00867)\end{array}$ & $\begin{array}{l}0.310^{* * *} \\
(0.0559)\end{array}$ & $\begin{array}{l}0.194^{* * *} \\
(0.0554)\end{array}$ & $\begin{array}{l}0.212^{* * *} \\
(0.0692)\end{array}$ & $\begin{array}{l}0.0486^{* * *} \\
(0.00213)\end{array}$ \\
\hline HDDS_lag33 & & & $\begin{array}{c}-0.0127^{* * *} \\
(0.00263)\end{array}$ & $\begin{array}{c}-0.00760^{* * *} \\
(0.00262)\end{array}$ & $\begin{array}{c}-0.0101^{* * *} \\
(0.00348)\end{array}$ & $\begin{array}{c}-0.00175^{* * *} \\
(0.000101)\end{array}$ \\
\hline Drought $(=1)$ & & & & $\begin{array}{c}-0.347^{* * *} \\
(0.0505)\end{array}$ & $\begin{array}{c}0.144 \\
(0.115)\end{array}$ & $\begin{array}{c}-0.0544^{* * *} \\
(0.00121)\end{array}$ \\
\hline Female head $(=1)$ & & & & $\begin{array}{l}-0.00517 \\
(0.0471)\end{array}$ & $\begin{array}{l}-0.0511 \\
(0.104)\end{array}$ & $\begin{array}{c}-0.00122 \\
(0.000908)\end{array}$ \\
\hline Age of HH Head & & & & $\begin{array}{c}-0.00395 \\
(0.00755)\end{array}$ & $\begin{array}{l}-0.0127 \\
(0.0148)\end{array}$ & $\begin{array}{c}-0.00110^{* * *} \\
(0.000146)\end{array}$ \\
\hline Age $^{2}$ & & & & $\begin{array}{c}4.21 \mathrm{e}-05 \\
(6.95 \mathrm{e}-05)\end{array}$ & $\begin{array}{c}0.000139 \\
(0.000145)\end{array}$ & $\begin{array}{c}1.20 \mathrm{e}-05^{* * *} \\
(1.32 \mathrm{e}-06)\end{array}$ \\
\hline Dependency Ratio & & & & $\begin{array}{c}-0.00598 \\
(0.0248)\end{array}$ & $\begin{array}{l}-0.0277 \\
(0.0550)\end{array}$ & $\begin{array}{c}-0.00296^{* * *} \\
(0.000453)\end{array}$ \\
\hline Education of HH Head & & & & $\begin{array}{l}0.0654^{* * *} \\
(0.00921)\end{array}$ & $\begin{array}{l}0.00562 \\
(0.0175)\end{array}$ & $\begin{array}{c}0.0171^{* * *} \\
(0.000218)\end{array}$ \\
\hline Livestock owned (TLU & & & & $\begin{array}{l}-0.00163 \\
(0.00133)\end{array}$ & $\begin{array}{c}-0.00506^{* *} \\
(0.00234)\end{array}$ & $\begin{array}{c}-0.000521^{* * *} \\
(3.86 \mathrm{e}-05)\end{array}$ \\
\hline Religion \& Nomadic St & us Controls & & & $\mathrm{Y}$ & $\mathrm{Y}$ & $\mathrm{Y}$ \\
\hline Constant & $\begin{array}{c}3.816^{* * *} \\
(0.117)\end{array}$ & $\begin{array}{c}6.236^{* * *} \\
(0.434)\end{array}$ & $\begin{array}{c}9.648^{* * *} \\
(0.878)\end{array}$ & $\begin{array}{c}9.015^{* * *} \\
(0.890)\end{array}$ & $\begin{array}{c}4.694^{* * *} \\
(0.993)\end{array}$ & $\begin{array}{l}0.870^{* * *} \\
(0.0329)\end{array}$ \\
\hline $\begin{array}{l}\text { Observations } \\
\text { R-squared }\end{array}$ & $\begin{array}{c}3,278 \\
0.22 \\
\end{array}$ & $\begin{array}{c}3,278 \\
0.23 \\
\end{array}$ & $\begin{array}{c}3,278 \\
0.24 \\
\end{array}$ & $\begin{array}{c}3,278 \\
0.32\end{array}$ & $\begin{array}{l}3,278 \\
0.037 \\
\end{array}$ & 3,278 \\
\hline
\end{tabular}


Table 2: OLS estimates of Mid-Upper Arm Circumference (MUAC), Variance (MUAC), \& Food Security

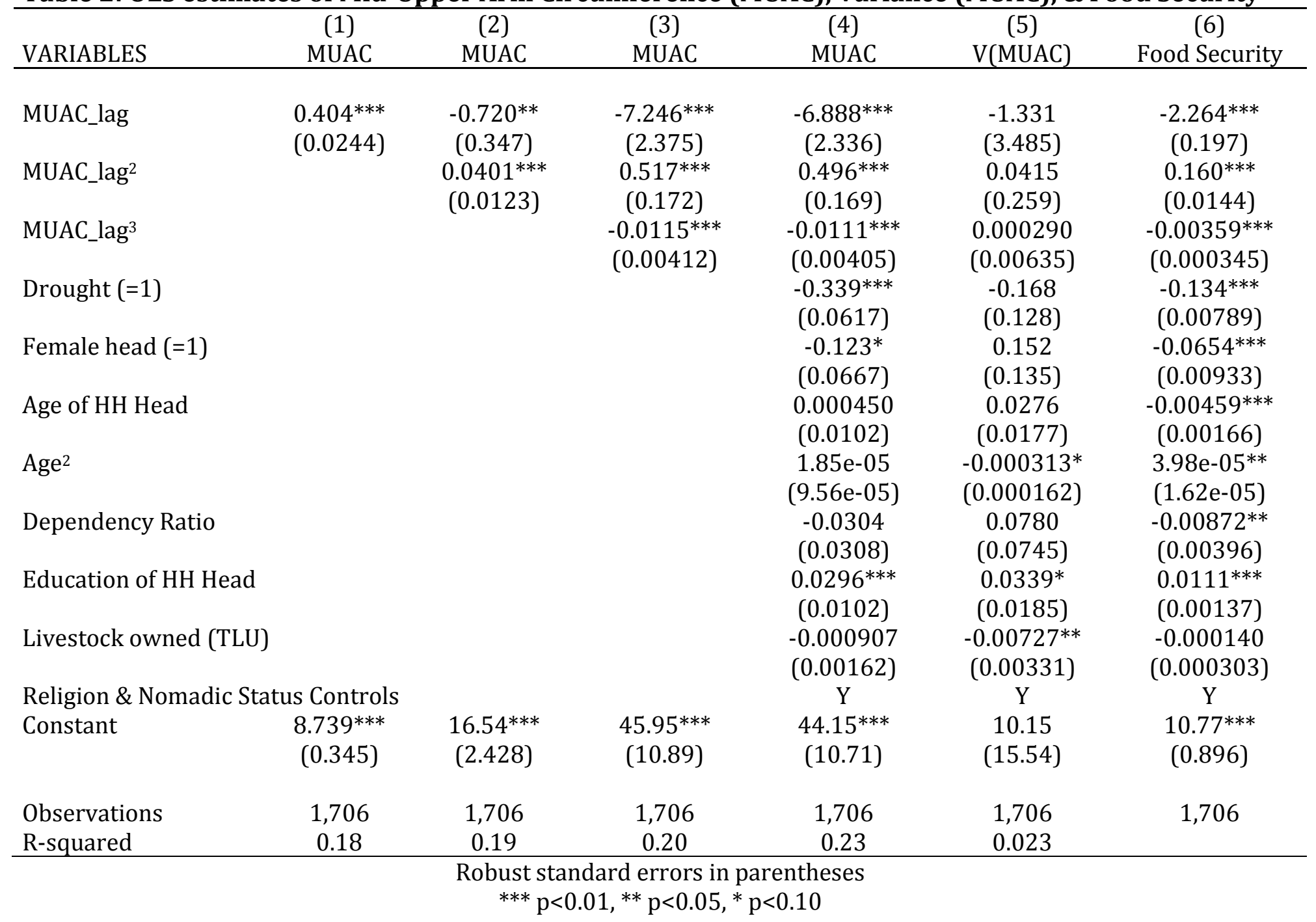


Table 3: Estimates of Targeting Accuracy - HDDS

\begin{tabular}{llllll}
\hline$\underline{\mathrm{P}}$ & $\begin{array}{l}\text { Correctly } \\
\text { Not Targeted }\end{array}$ & $\begin{array}{l}\text { Correctly } \\
\text { Targeted }\end{array}$ & TI Error & TII Error & $\begin{array}{l}\text { Sum of } \\
\text { Errors }\end{array}$ \\
\hline 0.15 & 0.266 & 0.503 & 0.088 & 0.143 & 0.231 \\
0.20 & 0.198 & 0.566 & 0.156 & 0.080 & 0.236 \\
0.25 & 0.122 & 0.609 & 0.231 & 0.037 & 0.268 \\
0.30 & 0.056 & 0.644 & 0.298 & 0.002 & 0.300 \\
Standard & 0.209 & 0.536 & 0.145 & 0.110 & 0.255
\end{tabular}

Table 4: Estimates of Targeting Accuracy - MUAC

\begin{tabular}{llllll}
\hline$\underline{\mathrm{P}}$ & $\begin{array}{l}\text { Correctly } \\
\text { Not Targeted }\end{array}$ & $\begin{array}{l}\text { Correctly } \\
\text { Targeted }\end{array}$ & TI Error & TII Error & $\begin{array}{l}\text { Sum of } \\
\text { Errors }\end{array}$ \\
\hline 0.15 & 0.447 & 0.083 & 0.038 & 0.405 & 0.443 \\
0.20 & 0.386 & 0.212 & 0.098 & 0.277 & 0.375 \\
0.25 & 0.326 & 0.322 & 0.159 & 0.167 & 0.326 \\
0.30 & 0.220 & 0.379 & 0.265 & 0.110 & 0.375 \\
Standard & 0.277 & 0.356 & 0.189 & 0.121 & 0.311
\end{tabular}

